\title{
Elementary Economic Systems in Material Agent Societies
}

\author{
Sistemas Econômicos Elementares em Sociedades de Agentes Materiais
}

\author{
Antônio Carlos da Rocha Costa ${ }^{1 *}$
}

\begin{abstract}
This paper formally characterizes the elementary economic systems of material agent societies, on the bases of the notions of (individual and group) elementary economic behavior, elementary economic exchange and elementary economic process. The equilibrium of an elementary economic system is defined in terms of the equilibrium of the set of group elementary economic processes that constitute such system. A case study illustrates the proposed concepts.

Keywords: Agent societies - Material agent societies - Elementary economic systems - Elementary economic processes - Elementary economic exchanges - Elementary economic behaviors

Resumo: Este artigo caracteriza formalmente os sistemas econômicos elementares das sociedades de agentes materiais, tendo por base as noções de comportamento econômico elementar, troca econômica elementar e processo econômico elementar (tanto individuais como grupais). O equilíbrio de um sistema econômico elementar é definido em termos do equilíbrio do conjunto dos processos econômicos elementares grupais que constitui tal sistema. Um estudo de caso ilustra os conceitos propostos.

Palavras-Chave: Sociedade de agentes - Sociedade de agentes materiais - Sistemas econômicos elementares - Processos econômicos elementares - Trocas econômicas elementares - Comportamentos econômicos elementares

${ }^{1}$ Programa de Pós-Graduação em Computação,Universidade Federal do Rio Grande - FURG, Brazil

*Corresponding author: ac.rocha.costa@gmail.com

DOI: http://dx.doi.org/10.22456/2175-2745.86534 • Received: 09/09/2018 • Accepted: 06/05/2019

CC BY-NC-ND 4.0 - This work is licensed under a Creative Commons Attribution-NonCommercial-NoDerivatives 4.0 International License.
\end{abstract}

\section{Introduction}

\subsection{Contextualization}

In a previous paper [1], we have introduced the concepts of material agent societies and energy systems of material agent societies. The concept of energy systems assumes that energy is produced by, and distributed to, the material agents of material agent societies in the form of energy objects. The definitions adapt to the realm of material agent societies a reductive reading of some of the main concepts in Hanna Arendt's Human Condition [2].

The above two concepts, however, do not determine in any particular way how producers and consumers of energy objects can interact to produce and distribute such objects. To provide one such way, we focus in the present paper $^{1}$ on one particular mode of distribution of energy objects, namely, elementary economic processes (akin to Fernand Braudel's infra-economic processes [3]). We say that the set of elementary economic processes of a material agent society constitutes the elementary economic system of that society.

\footnotetext{
${ }^{1}$ This paper is a completely revised and extended version of the paper with the same title presented at the Workshop-School on Agents, their Environments and Applications (WESAAC 2018) - see <http://uece.wesaac.com>
}

To allow for elementary economic processes to occur in a material agent society, we require that the material agents be capable of producing other types of objects, besides energy objects, so that different kinds of objects can be exchanged for each other in the elementary economic exchanges that constitute those elementary economic processes.

For simplicity, in this paper we consider just one other type of objects, besides energy objects. We call them chips. Elementary economic processes are assumed, thus, to involve just the exchange of energy objects for chips, and vice-versa.

\subsection{Structure of the Paper}

The paper is structured as follows. Section 2 summarizes the concepts of material agent, material agent society, energy system of material agent society.

Section 3 discusses informally the concepts of elementary economic behavior and elementary economic exchange.

Sections 4 and 5 respectively introduce formal models for individual elementary economic behaviors and individual elementary economic exchanges. Section 6 , a formal model for individual elementary economic process.

Section 7 introduces a formal model for group elementary economic behaviors and exchange processes. Section 8 , a 
formal model for group elementary economic processes.

The main subject of the paper, the formal model of elementary economic system, is introduced, then, in Section 9.

Section 10 illustrates the application of the formal models introduced in the paper to the economic modeling and analysis of some aspects of ecological systems.

Section 11 is the Conclusion.

\section{Material Agent Societies and their En- ergy Systems}

We first summarize the concepts of material agent, material agent society and energy systems of material agent societies as these concepts were introduced in [1].

We say that an agent is a material agent whenever that agent has a material body, that is, a body that requires energy for its operation. We call material agent society any agent society whose agents are all material agents.

We consider here only material agent societies organized around an energy system, i.e., a particular social subsystem capable of producing and distributing energy objects within the society, but in such a way that it guarantees that the society is energetically autonomous ${ }^{2}$.

We call energy producer any material agent that participates in the operation of that energy system. As in [1], we assume that all producers are energetically self-sufficient, that is, are capable of producing all the energy they need for their own operation. The other material agents of the society, are said to be energy consumers.

\section{Elementary Economic Behaviors and Exchanges}

We take George Homans' model of social behaviors and exchanges [4] as the operational model on the basis of which we define elementary economic behaviors and exchanges. This way, our elementary economical model builds on the assumption that any material agent mag is capable of performing the following two types of actions:

- deliver an object to another agent at a time $t$, denoted by deliver ${ }^{t}$ ( $m a g, o b j, \mathrm{mag}^{\prime}$ ), where $\mathrm{mag}$ is the deliverer, and $m a g^{\prime}$ is the receiver, of the object $o b j$;

- receive an object from another agent at a time $t$, denoted by receive ${ }^{t}$ ( $\mathrm{mag}, \mathrm{obj}_{\mathrm{mag}}{ }^{\prime}$ ), where $\mathrm{mag}$ is the receiver, and $m a g^{\prime}$ is the deliverer, of the object $o b j$.

Besides, we assume that each material agent is capable, for each type of existent object, to account for the sum total of

\footnotetext{
${ }^{2}$ A material agent society is said to be energetically self-sufficient whenever the society is organized in a way that allows it to produce all the energy objects its material agents need to perform all the social functions that were assigned to them in that society. It is said to be energetically autonomous if it is energetically self-sufficient and it can coordinate by itself the production and distribution of its energy objects - see [1].
}

objects of that type that it has sent, received, or consumed, at each time.

Homans' model is heavily based on Burrhus Skinner's notion of operant conditioning [5]. Thus, a central feature of our model is a reinforcement process of sequences of actions of delivering objects to another material agent (deliver actions) by sequences of actions of receiving objects of other types from that material agent in return (receive actions).

More precisely, reinforcement processes are taken to operate between the temporal rates of those two sequences, that is, between the temporal rate at which the delivering operations are performed, and the temporal rate at which the receiving operations are performed.

In consequence, an operational feature of material agent societies that is required for the proper functioning of such reinforcement processes is that the elementary economic processes of those societies be cyclic, that is, that they be persistent processes endowed with a periodic structure.

\section{Individual Elementary Economic Be- haviors}

In this section, we sketch a formal theory of individual elementary economic behaviors of material agents. We leave for Sect. 8 the extension of the theory to elementary economic behaviors of groups of material agents.

\subsection{Terms for Denoting Individual Elementary Eco- nomic Behaviors}

The following variables range over the following sets (variables may appear in expressions with various types of decorations):

- $m a g$, ranging over the set Mag of material agents;

- beh, ranging over the set Beh of behaviors of material agents;

- afval, ranging over the set AfVal of affective values of material agents;

- exch, ranging over the set Exch of exchanges between material agents ;

- obj, ranging over the set Obj of objects that may be exchanged by material agents;

- $p, q, \ldots$, ranging over the set Sit of social situations in a material agent society;

- $t$ and $\tau$, ranging over the linearly ordered set $\mathrm{T}=\{0,1, \ldots\}$ of time instants.

Behaviors and affective values may be assigned to definite material agents:

- mag.beh: a behavior of the definite material agent mag;

- mag.afval: an affective value of the definite material agent mag. 
The rate of performance of a behavior beh is denoted by the operator " \langle\rangle " applied to that behavior: $\langle b e h\rangle$.

\subsection{Basic formulas}

Basic formulas have one of the following forms:

(a) statements about rates of performances of behaviors, or about tendencies of variation in such rates, thus:

- $\langle b e h\rangle:$ behavior has a defined rate of performance;

- $\langle b e h\rangle \mathrm{T}$ : behavior has a high rate of performance;

- $\langle$ beh $\rangle \boxminus$ : behavior has a medium rate of performance;

- $\langle b e h\rangle_{\perp}$ : behavior has a low rate of performance;

- $\langle b e h\rangle \uparrow:$ behavior has an increasing rate of performance;

- $\langle$ beh $\rangle \downarrow$ : behavior has a decreasing rate of performance;

(b) statements about affective assessments of rates of performances of behaviors, in the form:

$\left\langle\operatorname{mag}_{1} \cdot b e h\right\rangle_{p}\left[\operatorname{mag}_{2} \cdot a f v a l\right]_{q}$

whose meaning is that the rate of the behavior beh of the material agent $\mathrm{mag}_{1}$ has a defined value, in situation $p$, and that such rate of behavior is evaluated with affective value afval by the material agent $\mathrm{mag}_{2}$, in situation $q$. The possible values for affective values afval are: $\{-, 0,+\}$, each with its intuitive reading.

If $p=q$, one may write: $\langle$ mag.beh $\rangle[\text { mag.afval }]_{p}$. All the components of the formula are optional, except for the $\langle$ beh $\rangle$ component.

In particular, $\langle b e h\rangle[]$, the formula just says that the rate of performance of the behavior beh of an unspecified material agent, performed in an unspecified situation, is evaluated in an unspecified way, also in an unspecified situation, by some unspecified material agent.

The following illustrate some of the formal variations of such formulas:

- definiteness of the rate of a behavior :

- any formula in the set:

$$
\{\langle\text { beh }\rangle\} \cup\left\{\left\langle\text { beh }_{i}\right\rangle\right\}_{i \in \mathbb{N}}
$$

meaning that $b e h\left(\right.$ or $\left.b e h_{i}\right)$ has a defined rate of performance;

- situated definiteness of the rate of a behavior:

- any formula in the set:

$$
\left\{\langle b e h\rangle_{p}\right\} \cup\left\{\left\langle b e h_{i}\right\rangle_{p}\right\}_{i, p \in \mathbb{N}}
$$

meaning that $b e h$ (or $b e h_{i}$ ) has a defined rate of performance in situation $p$;
- definiteness of the rate of a behavior of a particular material agent:

- any formula in the set:

$$
\left\{\left\langle\text { mag }_{i} \cdot \text { beh }_{j}\right\rangle\right\}_{i, j \in \mathbb{N}}
$$

- the meaning of $\left\langle\operatorname{mag}_{i}\right.$. beh $\left._{j}\right\rangle$ is that the rate of the behavior $b h_{j}$ of material agent $m a g_{i}$ has a defined value;

- situated definiteness of the rate of a behavior of a particular material agent:

- any formula in the set $\left\{\left\langle\operatorname{mag}_{i} \cdot b_{e} h_{j}\right\rangle_{p}\right\}_{i, n, p \in \mathbb{N}}$, meaning that $b e h_{j}$ of $m a g_{i}$ has a defined rate of performance in situation $p$

- affective evaluation of the rate of a behavior:

- any formula in the set:

$$
\left\{\langle\text { beh }\rangle[\text { afval }] \cup\left\{\left\langle\text { beh }_{i}\right\rangle\left[\text { afval }_{j}\right]\right\}_{i, j \in \mathbb{N}}\right.
$$

- the meaning of $\langle$ beh $\rangle[a f v a l]$ (or $\left\langle b h_{i}\right\rangle\left[a_{\text {fval }}\right]$ ) is that the defined rate of behavior beh (or $b e h_{i}$ ) is affectively evaluated with value afval (or $a f v a l_{j}$ ) by an unspecified material agent, in an unspecified situation;

- situated affective evaluation of the rate of a behavior: - any formula in the set:

$$
\left\{\langle\text { beh }\rangle\left[\text { afval }_{p}\right\} \cup\left\{\left\langle\text { beh }_{i}\right\rangle\left[\text { afval }_{j}\right]_{p}\right\}_{p \in \mathbb{N}}\right.
$$

- the meaning of $\langle$ beh $\rangle[a f v a l]_{p}$ (or $\left\langle b e h_{i}\right\rangle\left[a f v a l_{j}\right]_{p}$ ) is that the defined rate of behavior beh (or $b e h_{i}$ ) is evaluated with affective value afval (or $a f v a l$ ) by an unspecified material agent, in situation $p$;

- affective evaluation of the rate of a behavior of a particular material agent by an unspecified material agent: - any formula in the set:

$$
\{\langle\text { mag.beh }\rangle[\text { afval }]\} \cup\left\{\left\langle\text { mag }_{i} . \text { beh }_{j}\right\rangle\left[\text { afval }_{k}\right]\right\}_{i, j, k \in \mathbb{N}}
$$

- meaning that $\langle m a g . b e h\rangle$ (or $\left\langle m a g_{i} \cdot b e h_{j}\right\rangle$ ) has a defined rate of performance, and is evaluated with affective value afval (or $a f v a l_{k}$ ) by an unspecified material agent;

- affective evaluation of the rate of a behavior by a specified material agent:

- any formula in the set:

$$
\{\langle\text { beh }\rangle[\text { mag.afval }]\} \cup\left\{\left\langle\text { beh }_{i}\right\rangle\left[\text { mag }_{j} . \text { afval }_{k}\right]\right\}_{i, j, k \in \mathbb{N}}
$$

- meaning that the rate of beh (or $b e h_{i}$ ) has a defined value and is evaluated by material agent $m a g$ (or $\mathrm{mag}_{j}$ ) with affective value afval (or $a f v a l_{k}$ );

- situated affective evaluation of the rate of a behavior by a specified material agent:

- any formula in the set:

$$
\left\{\langle\text { beh }\rangle[\text { mag.afval }]_{p}\right\} \cup\left\{\left\langle\text { beh }_{i}\right\rangle\left[\text { mag }_{j} \cdot \text { afval }_{k}\right]_{p}\right\}_{i, j, k, p \in \mathbb{N}}
$$

- meaning that the rate of $b e h$ (or $b e h_{i}$ ) has a defined value and is evaluated by material agent $m a g$ (or $\mathrm{mag}_{j}$ ) with affective value afval (or $a f v a l_{k}$ ), in situation $p$. 


\subsection{Compound formulas}

There are three ways of composing formulas: (a) propositional compositions of formulas; (b) functional dependence compositions of formulas; and (c) partial orderings of rates of behaviors and of affective evaluations of rates of behaviors.

(a) The propositional composition of formulas is given by the usual propositional operators $(\neg, \wedge, \vee, \Rightarrow, \Leftrightarrow, \ldots)$, assumed to have their usual precedence degrees.

The meaning of $\neg\langle b e h\rangle$ is that it is false that the behavior $\langle b e h\rangle$ has a defined rate, i.e., it is false that the behavior beh is in execution. The formula $\neg\langle b e h\rangle[a f v a l]$ should be read as $\neg(\langle b e h\rangle[$ afval $])$, that is, the operator of affective evaluation has precedence over $\neg$. The same happens with the other propositional operators, so that to express the simultaneous affective evaluation of two behaviors one should write $\left(\left\langle\right.\right.$ beh $\left._{i}\right\rangle \wedge\left\langle\right.$ beh $\left.\left._{j}\right\rangle\right)[$ afval $]$.

(b) Functional dependence compound formulas express monotonic qualitative functional dependences between two rates of performance of behaviors. They are built with the functional dependence operators $\nearrow$ and $\searrow$.

The functional dependence compound formulas have the basic forms:

$$
\left\langle b e h_{i}\right\rangle \nearrow\left\langle b e h_{j}\right\rangle \text { and }\left\langle b e h_{i}\right\rangle \searrow\left\langle b e h_{j}\right\rangle
$$

The meaning of $\left\langle b e h_{i}\right\rangle \rtimes\left\langle b e h_{j}\right\rangle$ is that: (a) the rates of performance of $b e h_{i}$ and of $b e h_{j}$ are both defined, and (b) the rate of beh $h_{j}$ monotonically increases with the rate of beh $h_{i}$. Correspondingly, the meaning of $\left\langle b e h_{i}\right\rangle \searrow\left\langle b e h_{j}\right\rangle$ is that the two rates of behaviors are related in a monotonically decreasing way.

The possible decorations of the functional dependence compound formulas with situation indexes are as follows: $\left\langle m a g_{i} \cdot b e h_{i}\right\rangle \nearrow_{p}\left\langle m a g_{j} \cdot b e h_{j}\right\rangle$ and $\left.\left\langle m a g_{i} \cdot b e h_{i}\right\rangle\right\rangle_{p}\left\langle m a g_{j} \cdot b e h_{j}\right\rangle$. Notice that, since the functional dependence has to be determined in a single situation, the situation indexes of the two behaviors have to refer to the same situation.

There is no notion of functional dependence between affective evaluations of defined values of variables, given the assumption of evaluation autonomy of the material agents. So the only way functional dependence compound formulas may be decorated with affective evaluation operations is by indicating that the whole functional dependence is affectively evaluated. That is done through the general forms:

$$
\left[\left\langle\operatorname{mag}_{i} \cdot \mathrm{beh}_{i}\right\rangle \nearrow_{p}\left\langle\operatorname{mag}_{j} \cdot \mathrm{beh}_{j}\right\rangle\right]\left[\operatorname{mag}_{k} \cdot \text { afval }_{k}\right]
$$

and

$$
\left[\left\langle\operatorname{mag}_{i} \cdot \mathrm{beh}_{i}\right\rangle \searrow_{p}\left\langle\operatorname{mag}_{j} \cdot \mathrm{beh}_{j}\right\rangle\right]\left[\operatorname{mag}_{k} \cdot \mathrm{afval}_{k}\right]
$$

meaning that the indicated functional dependences are evaluated by material agent mag $_{k}$ with affective value $a f v a l_{k}$.

The decoration of affectively evaluated functional dependences with situation indexes is also possible, e.g.:

$$
\left[\left\langle\operatorname{mag}_{i} \cdot \mathrm{beh}_{i}\right\rangle_{\nearrow_{p}}\left\langle\operatorname{mag}_{j} \cdot \mathrm{beh}_{j}\right\rangle\right]\left[\operatorname{mag}_{k} \cdot a f v a l_{k}\right]_{q}
$$

(c) The ordering of rates of performance of behaviors, and of results of affective evaluations of rates of behaviors, is given by the partial order relation " $\leqslant$ ".

We assume that " $\leqslant$ " operates uniformly on affective values and on rates of performances of behaviors. Thus, we may write both afval $_{1} \leqslant$ afval $_{2}$ and $\left\langle\right.$ beh $\left._{1}\right\rangle \leqslant\left\langle b e h_{2}\right\rangle$.

For any behavior beh it holds that its lowest rate of performance (given by $\perp$ ), highest rate of performance (given by $\top$ ), and medium rate of performance (given by $\boxminus$ ) are ordered by the partial ordering relation " $\leqslant$ " as: $\perp \leqslant \boxminus \leqslant T$. For the affective values resulting from the affective evaluation of rates of behavior, we extend the use of " $\leqslant "$ in the following way:

$$
\begin{aligned}
& \left\langle\operatorname{mag}_{1} \cdot \text { beh }_{1}\right\rangle\left[\mathrm{mag}_{2} \cdot \mathrm{afval}_{2}\right]_{p} \leqslant\left\langle\mathrm{mag}_{3} \cdot a_{3}\right\rangle\left[\mathrm{mag}_{4} \cdot \mathrm{afval}_{4}\right]_{p} \Leftrightarrow \\
& \left\langle\operatorname{mag}_{1} \cdot \text { beh }_{1}\right\rangle\left[\mathrm{mag}_{2} \cdot \text { afval }_{2}\right]_{p} \wedge\left\langle\operatorname{mag}_{3} . a_{3}\right\rangle\left[\mathrm{mag}_{4} \cdot \text { afval }_{4}\right]_{p} \\
& \wedge \text { afval }_{2} \leqslant \text { afval }_{4}
\end{aligned}
$$

\subsection{Skinner's Individual Behavior Conditioning Rules}

The fundamental relation between behaviors, according to Skinner [5], is the relation of operant conditioning, that is, the relation through which an spontaneous behavior (an operant) is led to be performed in the context of, and in accordance to, a certain conditioner behavior.

The conditioning occurs because the conditioner behavior is assumed to represent a combination of events that is relevant for the internal functioning of the operant agent, so that it is capable of influencing (positively or negatively) the way that agent performs the operant behavior that is being conditioned.

Skinner's basic proposition (which is fully adopted by Homans) is:

An operant is conditioned by a conditioner whenever it happens that an increase or decrease in the rate of performance of the conditioner impacts the rate of performance of the operant behavior.

The usual interpretation of this proposition is that the operant agent evaluates (positively or negatively) the variation (increase or decrease) in the rate of performance of the conditioner behavior, and reacts by varying accordingly the rate of performance of the operant behavior.

The operant conditioning rules shown in Figure 1 attempt to formally capture some of the more specific operant conditioning propositions in Skinner's behavioral psychology [5].

The " $\rightarrow$ " symbol denotes the impact relation between the (positive or negative) evaluation, by $\mathrm{mag}_{1}$, of the variation (increase or decrease) in the rate of reception of the conditioner object $o b j_{1}$ from $\mathrm{mag}_{2}$, and the consequent variation (increase or decrease) in the rate of performance of the delivery of the object $o b j_{1}$ to $\mathrm{mag}_{2}$, by $m a g_{1}$.

We may use the abbreviations shown in Figure 2 for the positive or negative affective assessments of the rate of the conditioner behavior, which are shown in Figure 1.

The formal expression of Skinner's rules for emotional responses is given by the following formulas:

- $\left\langle\operatorname{mag}_{2} . \mathrm{obj}_{2}\right\rangle\left[\mathrm{mag}_{1} \cdot+\right] \wedge\left\langle\operatorname{mag}_{2} . \mathrm{obj}_{2} \perp\right\rangle \leadsto\left\langle\operatorname{mag}_{1} \cdot N\right\rangle$ - meaning that the withdrawal by the material agent 


$$
\begin{aligned}
& \left\langle\text { mag }_{1} . \text { receive }\left(\mathrm{mag}_{1}, \mathrm{obj}_{1}, \mathrm{mag}_{2}\right) \uparrow\right\rangle\left[\mathrm{mag}_{1} \cdot+\right] \leadsto\left\langle\mathrm{mag}_{1} \cdot \operatorname{deliver}\left(\mathrm{mag}_{1}, \mathrm{obj}_{2}, \mathrm{mag}_{2}\right) \uparrow\right\rangle \\
& \left\langle\operatorname{mag}_{1} . \text { receive }\left(\mathrm{mag}_{1}, \mathrm{obj}_{1}, \mathrm{mag}_{2}\right)_{\downarrow}\right\rangle\left[\mathrm{mag}_{1} .+\right] \sim\left\langle\mathrm{mag}_{1} \text {.deliver }\left(\mathrm{mag}_{1}, \mathrm{obj}_{2}, \mathrm{mag}_{2}\right) \uparrow\right\rangle \\
& \left\langle\mathrm{mag}_{1} \text {.receive }\left(\mathrm{mag}_{1}, \mathrm{obj}_{1}, \mathrm{mag}_{2}\right) \uparrow\right\rangle\left[\mathrm{mag}_{1}{ }^{-}-\right] \sim\left\langle\mathrm{mag}_{1} \text {.deliver }\left(\mathrm{mag}_{1}, \mathrm{obj}_{2}, \mathrm{mag}_{2}\right)_{\downarrow}\right\rangle \\
& \left\langle\text { mag }_{1} \text {.receive }\left(\mathrm{mag}_{1}, \mathrm{obj}_{1}, \mathrm{mag}_{2}\right) \downarrow\right\rangle\left[\mathrm{mag}_{1}{ }^{-}-\right] \leadsto\left\langle\mathrm{mag}_{1} \text {.deliver }\left(\mathrm{mag}_{1}, \mathrm{obj}_{2}, \mathrm{mag}_{2}\right)_{\downarrow}\right\rangle
\end{aligned}
$$

Figure 1. Usual interpretation of Skinner's basic rules formally presented.

$$
\begin{aligned}
& \left\langle m a g_{1} . \text { receive }\left(\mathrm{mag}_{1}, \mathrm{obj}_{2}, \mathrm{mag}_{2}\right)\right\rangle \rightarrow^{+}\left\langle\mathrm{mag}_{1} \text {.deliver }\left(\mathrm{mag}_{1}, \mathrm{obj}_{1}, \mathrm{mag}_{2}\right)\right\rangle \\
& \left\langle m a g_{1} \text {.receive }\left(\mathrm{mag}_{1}, \mathrm{obj}_{2}, \mathrm{mag}_{2}\right)\right\rangle \rightarrow^{-}\left\langle m a g_{1} \text {.deliver }\left(\mathrm{mag}_{1}, \mathrm{obj}_{1}, \mathrm{mag}_{2}\right)\right\rangle
\end{aligned}
$$

Figure 2. Abbreviations for the positive and negative affective assessments of conditioners by the operant agent.

$m a g_{2}$ of the positive reinforcer $o b j_{2}$ of some operant of material agent $\mathrm{mag}_{1}$ may release in $\mathrm{mag}_{1}$ a negative emotional behavior $N$.

- $\left\langle\operatorname{mag}_{2} . \mathrm{obj}_{2}\right\rangle\left[\mathrm{mag}_{1} \cdot+\right]\left\langle\mathrm{mag}_{2} . \mathrm{obj}_{2} T\right\rangle \sim\left\langle\operatorname{mag}_{1} \cdot P\right\rangle$ - meaning that the the presentation by the material agent $\mathrm{mag}_{2}$ of the positive reinforcer $\mathrm{obj}_{2}$ of some operant of material agent $\mathrm{mag}_{1}$ may release in $\mathrm{mag}_{1}$ some degree of a positive emotional behavior $P$.

\subsection{Homans' Conditioning Rules and their Elemen- tary Economic Interpretation}

George Homans adopted Skinner's theory as the behavioristic foundation of his social exchange theory [4]. In Homans' social interpretation of Skinner's conditioning rules, the operant is a concrete behavior that some agent directs toward another agent, and the conditioner is some affective reward that the latter directs toward the former.

In our economic interpretation of Homans' concept of social behavior, we recast both the operant and the conditioner behaviors to be sequences of actions of delivering and receiving objects (more precisely, energy objects and chips, respectively).

We introduce this economic interpretation as the set of conditioning rules for individual elementary economic behaviors shown in Figure 3. The rules are characterized by the type of the conditioning acting on the operant behavior ("+" or "-") and by the level of activity of the conditioner ("ד", "曰" or " $\perp ")$. The informal reading of those rules are as follows:

1. Rule $B C_{(+, \boxminus)}$ : If $m g_{1}$ evaluates positively $(+)$ the reception of $\mathrm{obj}_{2}$ from $\mathrm{mag}_{2}$, in return to $\mathrm{mag}_{1}$ delivering $o b j_{1}$ to $m a g_{2}$, and $m a g_{2}$ delivers $o b j_{2}$ to $m a g_{1}$ at $a$ regular temporal rate $(\boxminus)$ then: the more frequently $\mathrm{mag}_{2}$ delivers $o b j_{2}$ to $m a g_{1}$, the more frequently will $\mathrm{mag}_{1}$ deliver $o b j_{1}$ to $\mathrm{mag}_{2}$. Formally:

2. Rule $B C_{(+, T)}$ : If $m a g_{1}$ evaluates positively (+) the reception of $\mathrm{obj}_{2}$ from $\mathrm{mag}_{2}$, in return to $\mathrm{mag}_{1}$ delivering $o b j_{1}$ to $m a g_{2}$, and $m a g_{2}$ delivers $o b j_{2}$ to $m a g_{1}$ at a very high temporal rate $(\mathrm{T})$ then: the more frequently $\mathrm{mag}_{2}$ delivers $o b j_{2}$ to $m a g_{1}$, the less frequently will $m a g_{1}$ deliver $\mathrm{obj}_{1}$ to $\mathrm{mag}_{2}$. Formally:

3. Rule $B C_{(+, \perp)}$ : If $\mathrm{mag}_{1}$ evaluates positively $(+)$ the reception of $\mathrm{obj}_{2}$ from $\mathrm{mag}_{2}$, in return to $\mathrm{mag}_{1}$ delivering $o b j_{1}$ to $m a g_{2}$, and $m a g_{2}$ delivers $o b j_{2}$ to $m a g_{1}$ at a very low temporal rate $(\perp)$ then: the more frequently $\mathrm{mag}_{2}$ delivers $o b j_{2}$ to $m a g_{1}$, the more frequently will $m a g_{1}$ deliver $o b j_{1}$ to $\mathrm{mag}_{2}$. Formally:

4. Rule $B C_{-}$: If $\mathrm{mag}_{1}$ evaluates negatively (-) the reception of $\mathrm{obj}_{2}$ from $\mathrm{mag}_{2}$, in return to $\mathrm{mag}_{1}$ delivering $o b j_{1}$ to $m a g_{2}$ then: the more frequently $m a g_{2}$ delivers $o b j_{2}$ to $m a g_{1}$, the less frequently will $m a g_{1}$ deliver $o b j_{1}$ to $\mathrm{mag}_{2}$. Formally:

5. Rule $B C_{\downarrow}$ : Any increase in frequency of a particular behavior beh $h_{1}$ by mag entails by that very fact a decrease in the frequency of any alternative behavior $b e h_{2}$ that mag can perform. In the rule, beh $[\mathrm{mag}]$ denotes the set of behaviors that mag is capable of performing.

\section{Individual Elementary Economic Ex- changes}

We call individual elementary economic exchanges the elementary economic exchanges performed between individual material agents. They should be distinguished from the group elementary economic exchanges, introduced in Section 7.

In this section, besides the concept of individual elementary economic exchanges, and its formal notation, we formally introduce the concepts of material outcome function, material equilibrium and operational equilibrium of individual elementary economic exchanges. 


$$
\begin{aligned}
& \left\langle\operatorname{mag}_{1} \text {.receive }\left(\mathrm{mag}_{1}, \mathrm{obj}_{2}, \mathrm{mag}_{2}\right)\right\rangle \rightarrow^{+}\left\langle\mathrm{mag}_{1} \text {.deliver }\left(\mathrm{mag}_{1}, \mathrm{obj}_{1}, \mathrm{mag}_{2}\right)\right\rangle
\end{aligned}
$$

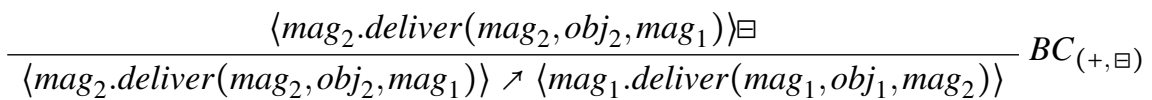

$$
\begin{aligned}
& \left\langle\operatorname{mag}_{1} \text {.receive }\left(\operatorname{mag}_{1}, \text { obj }_{2}, \mathrm{mag}_{2}\right)\right\rangle \rightarrow^{+}\left\langle\operatorname{mag}_{1} \text {.deliver }\left(\operatorname{mag}_{1}, \mathrm{obj}_{1}, \mathrm{mag}_{2}\right)\right\rangle \\
& \frac{\left\langle\mathrm{mag}_{2} \text {.deliver }\left(\mathrm{mag}_{2}, \mathrm{obj}_{2}, \mathrm{mag}_{1}\right)\right\rangle \top}{\left\langle\mathrm{mag}_{2} \text {.deliver }\left(\mathrm{mag}_{2}, \text { obj }_{\mathrm{mag}}\right)\right\rangle \searrow\left\langle\mathrm{mag}_{1} \text {.deliver }\left(\mathrm{mag}_{1}, \text { beh }_{1} \mathrm{mag}_{2}\right)\right\rangle} B C_{(+, \top)} \\
& \left\langle\operatorname{mag}_{1} \text {.receive }\left(\operatorname{mag}_{1}, \text { obj }_{2}, \mathrm{mag}_{2}\right)\right\rangle \rightarrow^{+}\left\langle\operatorname{mag}_{1} \text {.deliver }\left(\mathrm{mag}_{1}, \mathrm{obj}_{1}, \mathrm{mag}_{2}\right)\right\rangle
\end{aligned}
$$

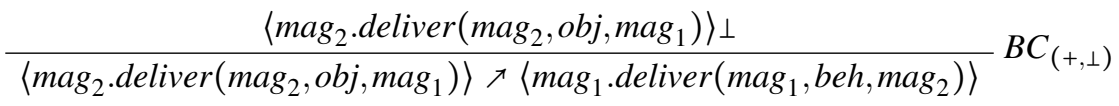

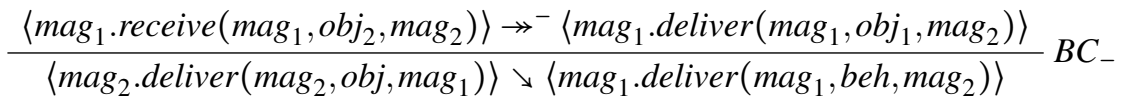

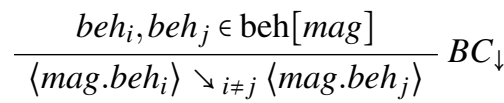

Figure 3. Operant conditioning rules for individual elementary economic behaviors.

\subsection{Terms for Denoting Individual Elementary Eco- nomic Exchanges}

An individual elementary economic exchange is a pair of operant conditionings acting between two material agents, $m a g_{1}$ and $m a g_{2}$, so that the delivery of the object $o b j_{1}$, by $\mathrm{mag}_{1}$ to $\mathrm{mag}_{2}$ acts as a conditioner to the delivery of the object $\mathrm{obj}_{2}$ by $\mathrm{mag}_{2}$ to $\mathrm{mag}_{1}$, and vice-versa.

We say that an individual elementary economic exchange between $\mathrm{mag}_{1}$ and $\mathrm{mag}_{2}$, involving the exchange of the objects $o b j_{1}$ and $o b j_{2}$ between them, is performed in the doubly positive mode of exchange if and only if:

1. $o b j_{1}$ is an energy object and $o b j_{2}$ is a chip, or vice-versa;

2. $\left\langle m a g_{1}\right.$.receive $\left.\left(\operatorname{mag}_{1}, \mathrm{obj}_{2}, \mathrm{mag}_{2}\right)\right\rangle \rightarrow^{+}$

$$
\left\langle\operatorname{mag}_{1} \text {.deliver }\left(\operatorname{mag}_{1}, \mathrm{obj}_{1}, \operatorname{mag}_{2}\right)\right\rangle
$$

3. $\left\langle\operatorname{mag}_{2}\right.$.receive $\left.\left(\mathrm{mag}_{2}, \mathrm{obj}_{1}, \mathrm{mag}_{1}\right)\right\rangle \rightarrow^{+}$

$$
\left\langle\operatorname{mag}_{2} \text {.deliver }\left(\mathrm{mag}_{2}, \mathrm{obj}_{2}, \mathrm{mag}_{1}\right)\right\rangle
$$

We denote such a doubly positively reinforced individual elementary economic exchange by:

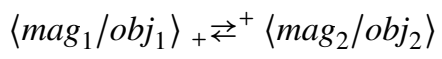

The vicissitudes of the performance of an individual elementary economic exchange (e.g., variations in the rate of reception of conditioners) may lead the material agents involved in it to change the way they evaluate the conditioners they receive from their partners. As a result, the following are other modes of exchange that may occur during the performance of an individual elementary economic exchange:

- mixed modes of exchange:

$$
\left\langle m a g_{1} / o b j_{1}\right\rangle_{-} \rightleftarrows^{+}\left\langle\operatorname{mag}_{2} / o b j_{2}\right\rangle
$$

and

$$
\left\langle m a g_{1} / o b j_{1}\right\rangle_{+} \rightleftarrows^{-}\left\langle\operatorname{mag}_{2} / o b j_{2}\right\rangle
$$

- doubly negative mode of exchange:

$$
\left\langle m a g_{1} / o b j_{1}\right\rangle_{-} \rightleftarrows^{-}\left\langle m a g_{2} / o b j_{2}\right\rangle
$$

\subsection{The Material Outcome of Individual Elementary Economic Exchanges}

Let $\mathrm{mag}_{1}$ and $\mathrm{mag}_{2}$ be two material agents performing a doubly positive individual elementary economic exchange of the form ie2exch $=\left\langle\operatorname{mag}_{1} / o b j_{1}\right\rangle_{+} \rightleftarrows^{+}\left\langle m a g_{2} / o b j_{2}\right\rangle$. Let obj $^{t}\left[\mathrm{mag}_{1}\right] \in \mathbb{N} \times \mathbb{N}$ and obj ${ }^{t}\left[\mathrm{mag}_{2}\right] \in \mathbb{N} \times \mathbb{N}$ be the amounts of objects of types $O b j_{1}$ and $O b j_{2}$ that each such material agent respectively has at the time $t$. The material outcome of the individual elementary economic exchange ie2exch, obtained between the times $t$ and $t^{\prime}>t$ is given by: 
moutcome $[\text { ie } 2 e x c h]_{t}^{t^{\prime}}=$

$$
\left(\mathrm{obj}^{t^{\prime}}\left[\mathrm{mag}_{1}\right]-\mathrm{obj}^{t}\left[\mathrm{mag}_{1}\right], \mathrm{obj}^{t^{\prime}}\left[\mathrm{mag}_{2}\right]-\mathrm{obj}^{t}\left[\mathrm{mag}_{2}\right]\right)
$$

where, for any material agent mag and any times $t$ and $t^{\prime}>t$, we have that ${ }^{3}$ :

$\mathrm{obj}^{t^{\prime}}[\mathrm{mag}]-\mathrm{obj}^{t}[\mathrm{mag}]=$

$\left(\mathrm{obj}^{\mathrm{t}^{\prime}}[\mathrm{mag}][1]-\mathrm{obj}^{\mathrm{t}}[\mathrm{mag}][1], \mathrm{obj}^{t^{\prime}}[\mathrm{mag}][2]-\mathrm{obj}^{t^{t}}[\mathrm{mag}][2]\right)$

with moutcome $[i e 2 e x c h]_{t}^{t^{\prime}} \in \mathbb{Z} \times \mathbb{Z}$, so that the material outcome of an individual elementary economic exchange can have negative components.

\subsection{Operational Equilibrium of Individual Elementary Economic Exchanges}

We say that the individual elementary economic exchange:

$$
i e 2 e x c h=\left\langle\operatorname{mag}_{1} / \operatorname{obj}_{1}\right\rangle_{+} \rightleftarrows^{+}\left\langle\operatorname{mag}_{2} / \mathrm{obj}_{2}\right\rangle
$$

which is performed at a time $t$, is operationally equilibrated at that time if and only if it holds, for each of the behaviors $\left\langle m a g_{1} / o b j_{1}\right\rangle$ and $\left\langle m a g_{2} / o b j_{2}\right\rangle$, that they are performed at a medium rate at that time, that is: $\left\langle\mathrm{mag}_{1} / o b j_{1}\right\rangle^{t} \boxminus$ and $\left\langle\mathrm{mag}_{2} / \mathrm{obj}_{2}\right\rangle^{t} \boxminus$.

We denote by opequil ${ }^{\tau}[i e 2 e x c h]$ the fact that the individual elementary economic exchange ie2exch is operationally equilibrated at the time $\tau$.

\section{Individual Elementary Economic Pro- cesses}

An individual elementary economic process is a time-indexed sequence of individual elementary economic exchanges, performed by two given material agents, as explained in this section.

\subsection{Sequential Composition of Operant Condition- ings of Individual Elementary Economic Behav- iors}

Operant conditionings between individual elementary economic behaviors can be sequentially composed, in the sense that a behavior $b e h_{2}$ that is conditioned by a behavior $b e h_{1}$ can, itself, condition a behavior $b e h_{3}$. In such situation, one can say that behavior $b e h_{1}$ also conditions behavior $b e h_{3}$.

Figure 4 shows the general rule defining such sequential composition, considering the possible positive or negative conditionings that the behaviors may have on each other, that is: $c_{1}, c_{2} \in\{+,-\}$.

\subsection{Sequential Composition of Individual Elemen- tary Economic Exchanges}

Individual elementary economic exchanges can also be sequentially composed. Figure 5 shows the general rule defining such sequential composition, considering the possible positive

\footnotetext{
${ }^{3}$ In the following, any reference to the $i$-th component of a tuple $X$ is denoted by $X[i]$.
}

or negative conditionings that the behaviors may have in each exchange, that is: $c_{1,2}, c_{2,1}, c_{2,3}, c_{3,2} \in\{+,-\}$.

Notice that the material agent $\langle\mathrm{mag}\rangle_{2}$ can act as an intermediary between the material agents $\mathrm{mag}_{1}$ and $\mathrm{mag}_{3}$ only if it can handle separately the exchange of $t w o$ objects, $o b j_{2}$ and $o b j_{2}^{\prime}$, each corresponding to each of its partner (even if those objects are of the same type).

\subsection{Chains of Individual Elementary Economic Ex- changes}

We call chain of individual elementary economic exchanges any finite sequence of compositions of individual elementary economic exchanges, of the form:

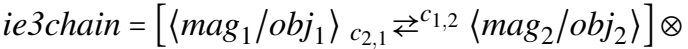

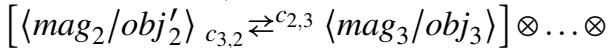

$$
\begin{aligned}
& {\left[\left\langle\operatorname{mag}_{n-1} / \mathrm{obj}_{n-1}^{\prime}\right\rangle_{c_{n, n-1}} \rightleftarrows^{c_{n-1, n}}\left\langle\operatorname{mag}_{n} / \operatorname{obj}_{n}\right\rangle\right]}
\end{aligned}
$$

where len[ie3chain $]=n-1$, for $n \geq 2$, is the length of the chain.

\subsection{Individual Elementary Economic Processes, For- mally Defined}

We call individual elementary economic process any finite time-indexed sequence of chains of individual elementary economic exchanges, where all chains in the sequence are of the same form and are performed by the same set of material agents (say $\left\{\mathrm{mag}_{1}, \mathrm{mag}_{2}, \ldots, \mathrm{mag}_{n}\right\}$ ).

We denote individual elementary economic processes by:

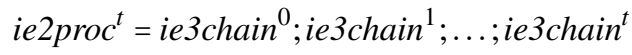

where $t \geq 0$ and for each $\tau \leq t$ it holds that:

$$
\begin{aligned}
\text { ie3chain }^{\tau}= & {\left[\left\langle\mathrm{mag}_{1} / \mathrm{obj}_{1}\right\rangle^{\tau}{ }_{c_{2,1}} \rightleftarrows^{c_{1,2}}\left\langle\mathrm{mag}_{2} / \mathrm{obj}_{2}\right\rangle^{\tau}\right] \otimes } \\
& {\left.\left[\left\langle\mathrm{mag}_{2} / \mathrm{obj}_{2}^{\prime}\right\rangle^{\tau}\right\rangle_{c_{3,2}} \rightleftarrows^{c_{2,3}}\left\langle\mathrm{mag}_{3} / \mathrm{obj}_{3}\right\rangle^{\tau}\right] \otimes \ldots \otimes } \\
& {\left[\text { varmag }_{n-1} / \mathrm{obj}_{n-1}^{\prime}{ }_{c_{n, n-1}} \rightleftarrows^{c_{n-1, n}}\left\langle\mathrm{mag}_{n} / \mathrm{obj}_{n}\right\rangle^{\tau}\right] }
\end{aligned}
$$

where:

- each $\left\langle m a g_{i} / o b j_{i}\right\rangle^{\tau} c_{j, i} \rightleftarrows^{c_{i, j}}\left\langle\mathrm{mag}_{j} / \operatorname{obj}_{j}\right\rangle^{\tau}$ is an individual elementary economic exchange that may occur at the time $\tau$;

- there is no cycle in ie2iproc ${ }^{t}$ (that is, $\operatorname{mag}_{i} \neq m a g_{j}$, for every $i, j \leq n$ );

- $t$ is the length of ie2proc, and $n$, the length of the chains, is the width of ie2proc.

We say that, for $0 \leq \tau \leq t$, the chain ie3chain ${ }^{\tau}$ is the process step that occurs at the time $\tau$ in ie2proc ${ }^{t}$.

\subsection{Material Outcome of Individual Elementary Eco- nomic Processes}

Given the individual elementary economic process ie2iproc ${ }^{t}$ we define its material outcome, regarding the time interval 


$$
\frac{\left\langle b e h_{1}\right\rangle \rightarrow^{c_{1}}\left\langle b e h_{2}\right\rangle \quad\left\langle b e h_{2}\right\rangle \rightarrow^{c_{2}}\left\langle b e h_{3}\right\rangle}{\left[\left\langle b e h_{1}\right\rangle \rightarrow^{c_{1}}\left\langle b e h_{2}\right\rangle\right] \otimes\left[\left\langle b e h_{2}\right\rangle \rightarrow^{c_{2}}\left\langle b e h_{3}\right\rangle\right]} S C B
$$

Figure 4. General rule for the sequential composition of operant conditionings of individual elementary economic behaviors.

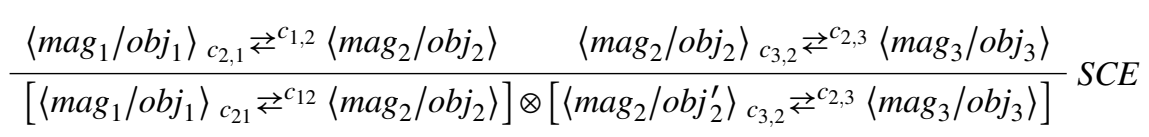

Figure 5. General rule for sequential composition of individual elementary economic exchanges.

$\left[\tau, \tau^{\prime}\right]$, for $0 \leq \tau<\tau^{\prime} \leq t$, in the following way:

moutcome $\left[i e 2 \operatorname{proc}^{t}\right]_{\tau}^{\tau^{\prime}}=$

$$
\left(\mathrm{obj}^{\tau^{\prime}}\left[\mathrm{mag}_{1}\right]-\mathrm{obj}^{\tau}\left[\mathrm{mag}_{1}\right], \ldots, \mathrm{obj}^{\tau^{\prime}}\left[\mathrm{mag}_{n}\right]-\mathrm{obj}^{\tau}\left[\mathrm{mag}_{n}\right]\right)
$$

We also define a reduced form of the material outcome of the individual elementary economic process $i e 2 p r o c$, as:

redmoutcome $[i e 2 p r o c]_{\tau}^{\tau^{\prime}}=$

$$
\left(\mathrm{obj}^{\tau^{\prime}}\left[m a g_{1}\right]-\mathrm{obj}^{\tau}\left[m a g_{1}\right], \mathrm{obj}^{\tau^{\prime}}\left[\mathrm{mag}_{n}\right]-\mathrm{obj}^{\tau}\left[\mathrm{mag}_{n}\right]\right)
$$

\subsection{Material Equilibrium of an Individual Elementary Economic Process}

We say that an individual elementary economic process $i e 2$ proc $^{t}$ is in material equilibrium, regarding a time interval $\left[\tau, \tau^{\prime}\right]$, if and only if its material outcome for that time interval is null, that is, moutcome $\left[i e 2 \text { proc }^{t}\right]_{\tau}^{\tau^{\prime}}=(0,0, \ldots, 0)$.

Material equilibrium means, thus, that the net amount of objects that were exchanged and consumed by the material agents that participate in $i e 2$ rroc $^{t}$, during that interval, is null.

\subsection{Operational Equilibrium of a Chain of Individual Elementary Economic Processes}

The operational equilibrium of a chain of individual elementary economic process, at a given time, is given by the fact that each of the exchanges that compose it is operationally equilibrated at that time. That is, the chain of individual elementary economic processes:

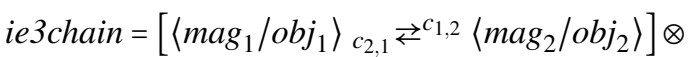

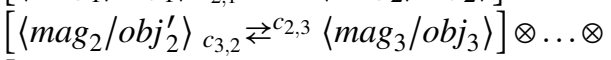

$$
\begin{aligned}
& {\left[\text { varmag }_{n-1} / \mathrm{obj}_{n-1}^{\prime} c_{n, n-1} \rightleftarrows^{c_{n-1, n}}\left\langle\mathrm{mag}_{n} / \mathrm{obj}_{n}\right\rangle\right]}
\end{aligned}
$$

is operationally equilibrated at the time $\tau$ if and only if each of the individual elementary economic exchanges that constitute it is operationally equilibrated at that time:

$$
\left.\forall\left\langle\operatorname{mag}_{i} / \operatorname{obj}_{i}\right\rangle \in \text { ie3chain }_{\text {opequil }}{ }^{\tau}\left[\left\langle\operatorname{mag}_{i} / \operatorname{obj}_{i}\right\rangle\right]\right)
$$

We denote by opequil ${ }^{\tau}[i e 3 c h a i n]$ the fact that ie3chain is operationally equilibrated at the time $\tau$.

\subsection{Operational Equilibrium of Individual Elementary Economic Processes}

We say that an individual elementary economic process is operationally equilibrated, at a given time, if and only if the process step that occurs in that individual elementary economic process, at that time, is operationally equilibrated. That is, the individual elementary economic process:

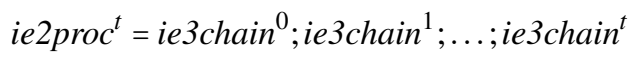

is operationally equilibrated at the time $\tau$ (with $0 \leq \tau \leq t$ ) if and only if the process step:

$$
\begin{aligned}
& \text { ie3chain }^{\tau}=\left[\left\langle\operatorname{mag}_{1} / \operatorname{obj}_{1}\right\rangle^{\tau}{ }_{c_{2,1}} \rightleftarrows^{c_{1,2}}\left\langle\mathrm{mag}_{2} / \mathrm{obj}_{2}\right\rangle^{\tau}\right] \otimes
\end{aligned}
$$

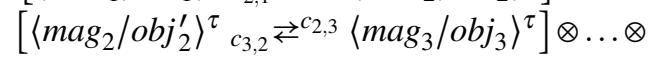

$$
\begin{aligned}
& {\left[\text { varmag }_{n-1} / \text { obj }_{n-1}^{\prime} c_{n, n-1} \rightleftarrows^{c_{n-1, n}}\left\langle\text { mag }_{n} / \text { obj }_{n}\right\rangle^{\tau}\right]}
\end{aligned}
$$

is operationally equilibrated, that is, opequil ${ }^{\tau}[$ ie3chain $]$.

We denote by opequil ${ }^{\tau}[i e 2$ proc $]$ the fact that ie2proc ${ }^{t}$ is operationally equilibrated at the time $\tau \leq t$. We denote by opequil $\tau_{\tau}^{\tau^{\prime}}[i e 2 p r o c]$ the fact that ie2proc ${ }^{t}$ is operationally equilibrated at each of the time instants of the interval $\left[\tau, \tau^{\prime}\right]$.

\subsection{Relationship between the Operational and the Material Equilibrium of an Individual Elementary Economic Process}

We remark that there is no necessary relation between the operational equilibrium and the material equilibrium of an individual elementary economic process.

The reason is that material equilibrium of individual elementary economic processes is defined in terms of variations in the amounts of objects that the involved material agents have at the beginning and at the end of the considered process, while the operational equilibrium of individual elementary economic processes is defined in terms of the rates of performances of the exchange behaviors that constitute them.

\section{Group Elementary Economic Behav- iors and Exchanges}

In this section, we extend for social groups of material agents the concepts of behavior and exchange that were introduced above for individual material agents. 


\subsection{Group Elementary Economic Behaviors and Ex- changes, Formally Defined}

The general form of individual elementary economic exchange introduced in Sect. 6, namely,

$$
\left\langle m a g_{1} / o b j_{1}\right\rangle_{c_{2,1}} \rightleftarrows^{c_{1,2}}\left\langle\mathrm{mag}_{2} / \mathrm{obj}_{2}\right\rangle
$$

is constituted by a combination of elementary economic behaviors performed by two individual material agents $\mathrm{mag}_{1}$ and $\mathrm{mag}_{2}$ ).

We can naturally extend the concept of elementary economic behavior to groups of material agents, considering that each such group operates as a unity, collectively delivering objects to another group, and collectively being reinforced by the reception of objects from that other group.

Let Mag and Mag' be two groups of material agents. The operation deliver ${ }^{t}\left(\mathrm{Mag}^{\prime} \mathrm{Obj}_{\mathrm{Mag}}{ }^{\prime}\right)$ indicates, then, the delivery of the set of objects $O b j$ by Mag to $\mathrm{Mag}^{\prime}$, at the time $t$, and the operation receive ${ }^{t}\left(\mathrm{Mag}_{\mathrm{O}} \mathrm{Obj}, \mathrm{Mag}^{\prime}\right)$ indicates that Mag receives the set $O b j$ from $\mathrm{Mag}^{\prime}$ at the time $t$.

A group elementary economic exchange between $\mathrm{Mag}_{1}$ and $M a g_{2}$, exchanging sets of objects $O b j_{1}$ and $O b j_{2}$, is denoted by: $\left\langle\mathrm{Mag}_{1} / \mathrm{Obj}_{1}\right\rangle_{c_{2,1}} \rightleftarrows^{c_{1,2}}\left\langle\mathrm{Mag}_{2} / \mathrm{Obj}_{2}\right\rangle$, with reinforcement signs $c_{1,2}, c_{2,1} \in\{+,-\}$.

\subsection{Material Outcome of Group Elementary Economic Processes}

Given the group elementary economic process ge2iproc ${ }^{t}$ we define its material outcome, regarding the time interval $\left[\tau, \tau^{\prime}\right]$, for $0 \leq \tau<\tau^{\prime} \leq t$, in the following way:

moutcome $\left[\text { ge } 2 p r o c^{t}\right]_{\tau}^{\tau^{\prime}}=$ $\left(\mathrm{Obj}^{\tau^{\prime}}\left[\mathrm{Mag}_{1}\right]-\mathrm{Obj}^{\tau}\left[\mathrm{Mag}_{1}\right], \ldots, \mathrm{Obj}^{\tau^{\prime}}\left[\mathrm{Mag}_{n}\right]-\mathrm{Obj}^{\tau}\left[\mathrm{Mag}_{n}\right]\right)$

We also define a reduced form of the material outcome of the individual elementary economic process ge2proc, as:

redmoutcome $[\text { ge2proc }]_{\tau}^{\tau^{\prime}}=$ $\left(\mathrm{Obj}^{\tau^{\prime}}\left[\mathrm{Mag}_{1}\right]-\mathrm{Obj}^{\tau}\left[\mathrm{Mag}_{1}\right], \mathrm{Obj}^{\tau^{\prime}}\left[\mathrm{Mag}_{n}\right]-\mathrm{Obj}^{\tau}\left[\mathrm{Mag}_{n}\right]\right)$

\subsection{Material Equilibrium of a Group Elementary Eco- nomic Process}

We say that a group elementary economic process ge2proc ${ }^{t}$ is in material equilibrium, regarding a time interval $\left[\tau, \tau^{\prime}\right]$ if and only if its material outcome function for that time interval is $n u l l$, that is, moutcome $\left[\text { geproc }^{t}\right]_{\tau}^{\tau^{\prime}}=(0,0, \ldots, 0)$.

Material equilibrium means, thus, that the net amount of objects that were exchanged and consumed by the material groups of material agents that participate in $g e 2$ proc $^{t}$, during that interval, is null. is operationally equilibrated at a time $t$ if and only if it holds, for each of the behaviors of $\mathrm{Mag}_{1}$ and $\mathrm{Mag}_{2}$, that they are performed at a medium rate at that time, that is, $\left\langle M a g_{1} / o b j_{1}\right\rangle^{t} \boxminus$ and $\left\langle\mathrm{Mag}_{2} / \mathrm{obj}_{2}\right\rangle^{t} \boxminus$.

We denote by opequil ${ }^{\tau}[$ ge2exch $]$ that the group elementary economic exchange ge2exch ${ }^{t}$ is operationally equilibrated at the time $\tau \leq t$.

Notice that the condition of operational equilibrium of a group elementary economic exchange is defined on the basis of a notion of group rate of performance of group behaviors (which we leave undefined here). Thus, the condition of operational equilibrium of a group elementary economic exchange does not require that the individual elementary economic exchanges that compose it be operationally equilibrated.

\section{Group Elementary Economic Pro- cesses}

In this section, we extend to social groups of material agents the concept of elementary economic process introduced above for individual material agents.

\subsection{Chains of Group Elementary Economic Exchanges}

We call chain of group elementary economic exchanges any finite sequence of compositions of group elementary economic

exchanges, of the form:

$$
\begin{aligned}
& \text { ge3chain }=\left[\left\langle\mathrm{Mag}_{1} / \mathrm{Obj}_{1}\right\rangle_{c_{2,1}} \rightleftarrows^{c_{1,2}}\left\langle\mathrm{Mag}_{2} / \mathrm{Obj}_{2}\right\rangle\right] \otimes \\
& {\left[\left\langle\mathrm{Mag}_{2} / \mathrm{Obj}_{2}^{\prime}\right\rangle_{c_{3,2}} \rightleftarrows^{c_{2,3}}\left\langle\mathrm{Mag}_{3} / \mathrm{Obj}_{3}\right\rangle\right] \otimes \ldots \otimes} \\
& {\left[\operatorname{varMag}_{n-1} / \mathrm{Obj}_{n-1}^{\prime} c_{n, n-1} \rightleftarrows^{c_{n-1, n}}\left\langle\mathrm{Mag}_{n} / \mathrm{Obj}_{n}\right\rangle\right]}
\end{aligned}
$$

where len[ge3chain $]=n-1$, for $n \geq 2$, is the length of the chain.

\subsection{Group Elementary Economic Processes, Formally Defined}

We call group elementary economic process any finite timeindexed sequence of chains of group elementary economic exchanges, where all chains in the sequence are of the same form, are performed by the same set of groups of material agents (say $\left\{\mathrm{Mag}_{1}, \mathrm{Mag}_{2}, \ldots, \mathrm{Mag}_{n}\right\}$ ).

We denote group elementary economic processes by:

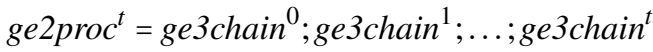

where $t \geq 0$ and for each $\tau \leq t$ it holds that:

$$
\begin{aligned}
& \text { ge3chain }^{\tau}=\left[\left\langle\mathrm{Mag}_{1} / \mathrm{Obj}_{1}\right\rangle_{c_{2,1}}^{\tau} \rightleftarrows^{c_{1,2}}\left\langle\mathrm{Mag}_{2} / \mathrm{Obj}_{2}\right\rangle^{\tau}\right] \otimes
\end{aligned}
$$

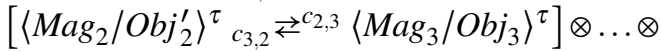

$$
\begin{aligned}
& {\left[\operatorname{varMag}_{n-1} / \mathrm{Obj}_{n-1}^{\prime}{ }^{\tau} c_{n, n-1} \rightleftarrows^{c_{n-1, n}}\left\langle\mathrm{Mag}_{n} / \mathrm{Obj}_{n}\right\rangle^{\tau}\right]}
\end{aligned}
$$

\subsection{Operational Equilibrium of Group Elementary Eco- where:} nomic Exchanges

We say that the group elementary economic exchange:

$$
\text { ge2exch }=\left\langle\mathrm{Mag}_{1} / \mathrm{Obj}_{1}\right\rangle_{+} \rightleftarrows^{+}\left\langle\mathrm{Mag}_{2} / \mathrm{Obj}_{2}\right\rangle
$$

- each $\left\langle\mathrm{Mag}_{i} / \mathrm{Obj}_{i}\right\rangle_{c_{j, i}}^{\tau} \rightleftarrows^{c_{i, j}}\left\langle\mathrm{Mag}_{j} / \mathrm{Obj}_{j}\right\rangle^{\tau}$ is a group elementary economic exchange that may occur at the time $\tau$ 
- there is no cycle in ge2iproc ${ }^{t}$ (that is, $\mathrm{Mag}_{i} \neq \mathrm{Mag}_{j}$, for every $i, j \leq n)$;

- $t$ is the length of ge2proc, and $n$, the length of the chains, is the width of ge2proc.

We say that, for $0 \leq \tau \leq t$, the chain ge3chain ${ }^{\tau}$ is the process step that occurs at the time $\tau$ in ge2proc ${ }^{t}$.

\subsection{Material Outcome of Group Elementary Economic Processes}

The material outcome of a group elementary economic process, relatively to the time interval $\left[\tau, \tau^{\prime}\right]$, with $0 \leq \tau<\tau^{\prime} \leq t$, is defined in the following way:

moutcome $\left[\operatorname{ge} 2 p r o c^{t}\right]_{\tau}^{\tau^{\prime}}=$

$$
\left(\mathrm{Obj}^{\tau^{\prime}}\left[\mathrm{Mag}_{1}\right]-\mathrm{Obj}^{\tau}\left[\mathrm{Mag}_{1}\right], \ldots, \mathrm{Obj}^{\tau^{\prime}}\left[\mathrm{Mag}_{n}\right]-\mathrm{Obj}^{\tau}\left[\mathrm{Mag}_{n}\right]\right)
$$

with the extension of the operation of subtraction to sets of objects held by groups of material agents, under the assumption that each such set of material agents is capable of accounting for the number of sets of objects that it has received from, and sent to, other sets of material agents.

The reduced form of the material outcome of the group elementary economic process ge2proc is the given by:

$$
\begin{aligned}
& \text { redmoutcome }[\text { ge2proc }]_{\tau}^{\tau^{\prime}}= \\
& \quad\left(\mathrm{Obj}^{\tau^{\prime}}\left[\mathrm{Mag}_{1}\right]-\mathrm{Obj}^{\tau}\left[\mathrm{Mag}_{1}\right], \mathrm{Obj}^{\tau^{\prime}}\left[\mathrm{Mag}_{n}\right]-\mathrm{Obj}^{\tau}\left[\mathrm{Mag}_{n}\right]\right)
\end{aligned}
$$

\subsection{Material Equilibrium of a Group Elementary Eco- nomic Process}

We say that a group elementary economic process ge2proc ${ }^{t}$ is in material equilibrium, regarding a time interval $\left[\tau, \tau^{\prime}\right]$ if and only if its material outcome for that time interval is null, that is, moutcome $\left[\operatorname{ge}^{2} \operatorname{proc}^{t}\right]_{\tau}^{\tau^{\prime}}=(0,0, \ldots, 0)$.

\subsection{Operational Equilibrium of a Chain of Group El- ementary Economic Processes}

The operational equilibrium of a chain of group elementary economic process, at a given time, is given by the fact that each of the exchanges that compose it is operationally equilibrated at that time. That is, the chain of group elementary economic processes:

$$
\begin{aligned}
& \text { ge3chain }=\left[\left\langle\mathrm{Mag}_{1} / \mathrm{Obj}_{1}\right\rangle_{c_{2,1}} \overleftrightarrow{c}^{c_{1,2}}\left\langle\mathrm{Mag}_{2} / \mathrm{Obj}_{2}\right\rangle\right] \otimes
\end{aligned}
$$

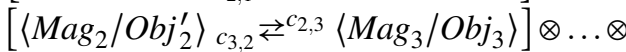

$$
\begin{aligned}
& {\left[\operatorname{varMag}_{n-1} / \mathrm{Obj}_{n-1}^{\prime} c_{n, n-1} \rightleftarrows^{c_{n-1, n}}\left\langle\mathrm{Mag}_{n} / \mathrm{Obj}_{n}\right\rangle\right]}
\end{aligned}
$$

is operationally equilibrated at the time $\tau$ if and only if each of the group elementary economic exchanges that constitute it is operationally equilibrated at that time.

That is, taking:

$$
\operatorname{ge3exch}_{i, j}=\left\langle\mathrm{Mag}_{i} / \mathrm{Obj}_{i}\right\rangle_{c_{j, i}} \rightleftarrows^{c_{i, j}}\left\langle\mathrm{Mag}_{j} / \mathrm{Obj}_{j}\right\rangle
$$

it holds that:

$$
\forall \operatorname{ge} 3 \operatorname{exch}_{i, j} \in \operatorname{ge} 3 \operatorname{chain}\left(\text { opequil }^{\tau}\left[\operatorname{ge} \operatorname{exch}_{i, j}\right]\right)
$$

We denote by opequil ${ }^{\tau}[$ ge3chain $]$ the fact that ge3chain is operationally equilibrated at the time $\tau$.

\subsection{Operational Equilibrium of Group Elementary Eco- nomic Processes}

We say that a group elementary economic process is operationally equilibrated, at a given time, if and only if the process step that occurs in that group elementary economic process, at that time, is operationally equilibrated. That is, the group elementary economic process:

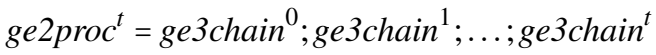

is operationally equilibrated at the time $\tau$ (with $0 \leq \tau \leq t$ ) if and only if the process step:

$$
\begin{aligned}
& \text { ge3chain }^{\tau}=\left[\left\langle\mathrm{Mag}_{1} / \mathrm{Obj}_{1}\right\rangle_{c_{2,1}}^{\tau} \rightleftarrows^{c_{1,2}}\left\langle\mathrm{Mag}_{2} / \mathrm{Obj}_{2}\right\rangle^{\tau}\right] \otimes \\
& {\left[\left\langle\mathrm{Mag}_{2} / \mathrm{Obj}_{2}^{\prime}\right\rangle^{\tau}{ }_{3,2} \rightleftarrows^{c_{2,3}}\left\langle\mathrm{Mag}_{3} / \mathrm{Obj}_{3}\right\rangle^{\tau}\right] \otimes \ldots \otimes} \\
& {\left[\operatorname{varMag}_{n-1} / \mathrm{Obj}_{n-1}^{\prime}{ }^{\tau} c_{n, n-1} \rightleftarrows^{c_{n-1, n}}\left\langle\mathrm{Mag}_{n} / \mathrm{Obj}_{n}\right\rangle^{\tau}\right]}
\end{aligned}
$$

is operationally equilibrated, that is, opequil ${ }^{\tau}[$ ge 3 chain $]$.

We denote by opequil ${ }^{\tau}[$ ge2proc $]$ the fact that ge2proc $^{t}$ is operationally equilibrated at the time $\tau$. We denote by opequil $\tau_{\tau}^{\tau^{\prime}}$ [ge2proc] the fact that $g e 2$ proc $^{t}$ is operationally equilibrated at each time instant of the interval $\left[\tau, \tau^{\prime}\right]$.

\section{Elementary Economic Systems}

Informally, the elementary economic system of a material agent society is, at a certain time, the set of group elementary economic processes that occur, at that time, among groups of material agents of that material agent society, possibly with some groups of agents participating in more than one group elementary economic process.

\subsection{Elementary Economic Systems, Formally Defined} The elementary economic system of a material agent society $M A g S o c$ whose population of material agents is Pop, is a time-indexed structure:

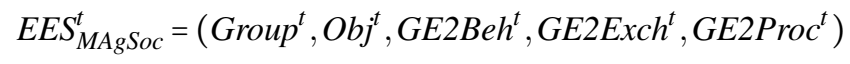

where ${ }^{4}$ :

- Group $^{t} \subseteq \wp(P o p)$ is the family of groups of material agents of Pop that can participate in the elementary economic group processes of GE2Proc ${ }^{t}$;

- $\mathrm{Obj}^{t} \subseteq \wp(\mathbf{O b j})$ is the family of sets of objects that the groups of material agents of Group $^{t}$ can exchange between them during the performance of the group elementary economic processes of GE2Proc ${ }^{t}$;

- GE2Beh ${ }^{t}$ is the set of group elementary economic behaviors that the groups of material agents of Group $^{t}$

\footnotetext{
${ }^{4} \wp(X)$ denotes the powerset of the set $X$.
} 
can perform during the performance of the group elementary economic processes of GE2Proc ${ }^{t}$;

- E2GExch ${ }^{t}$ is the set of group elementary economic exchanges that the groups of material agents of Group ${ }^{t}$ can perform during the performance of the group elementary economic processes of GE2Proc ${ }^{t}$;

- GE2Proc ${ }^{t}$ is the set of group elementary economic processes that the groups of material agents of Group ${ }^{t}$ can perform in MAgSoc at the time $t$.

\subsection{Material Outcome of Elementary Economic Sys- tems}

Given the elementary economic system:

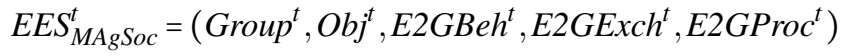

of the material agent society MAgSoc, we define the material outcome of EES ${ }_{M A g S o c}$ as follows: whenever the set EEGProc ${ }^{t}$ of elementary economic processes is given by $E_{E G P r o c}{ }^{t}=\left\{\operatorname{ge} \operatorname{proc}_{1}, \ldots\right.$, ge $\left.\operatorname{proc}_{n}\right\}$, with $n>1$, then the material outcome of EES ${ }_{M A g S o c}$ is given by the sum total of the material outcomes of its group elementary economic processes, that is:

$\operatorname{moutcome}\left[E E S_{M A g S o c}^{t}\right]=\sum_{i=1}^{i=n} \operatorname{moutcome}\left[\operatorname{ge} 2 p r o c_{i}\right]$

where the summation is performed in a component-wise way.

\subsection{Operational Equilibrium of Elementary Economic Systems}

We say that the elementary economic system:

$$
\operatorname{EES}_{M A g S o c}^{t}=\left(\operatorname{Group}^{t}, \mathrm{Obj}^{t}, G E 2 \mathrm{Beh}^{t}, G E 2 \operatorname{Exch}^{t}, G E 2 \operatorname{Proc}^{t}\right)
$$

is operationally equilibrated at the time $\tau$ (with $0 \leq \tau \leq t$ ) if and only if each of the group elementary economic process that constitute it is operationally equilibrated at that time, that is:

$\forall$ ge 2 proc $\in G E 2 \operatorname{Proc}^{\tau}$ (equil ${ }^{\tau}[$ ge 2 proc $]$ )

We denote by equil ${ }^{\tau}\left[E E S_{M A g S o c}\right]$ the fact that the elementary economic system $E E S_{M A g S o c}^{t}$ is equilibrated at time $\tau$. We denote by equil $\tau_{\tau}^{\tau^{\prime}}\left[E E S_{M A g S o c}\right]$ the fact that $E E S_{M A g S o c}$ is equilibrated at each time instant of the interval $\left[\tau, \tau^{\prime}\right]$.

\section{Ecosystems: A Case Study in Elemen- tary Economical Analysis}

We provide here elements for the elementary economical analysis of ecosystems. More precisely, we consider: (a) ecosystems as material agent societies; and (b) the interactional structure that constitute the operational part of the organizational structure of an ecosystem as an elementary economical system.
The casting of ecosystems as agent societies was introduced in [6]. The proposal for considering the interactional structure of an ecosystem as an elementary economical system is presented here for the first time.

Figure 6 pictures a general model of ecosystems. We base on it the elementary economical analysis that follows.

As in [6], we state that, formally, an ecosystem is a material agent society $E c o S y s^{t}=\left(\mathrm{Pop}^{t}, \mathrm{Org}^{t}, M E n v^{t}\right)$ where, for each time $t$ :

- Pop $^{t}$ is the populational structure of the ecosystem;

- $\mathrm{Org}^{t}$ is the organizational structure of the ecosystem;

- $M E n v^{t}$ is the ecosystem's material environment.

So, regarding the general model of ecosystem illustrated in Figure 6, the detailment of its material agent society-based model can be given as in Figure 7.

Clearly:

- Detrivores, Carnivores, Herbivores and Plants constitute the populational groups of the ecosystems;

- the Sun and the Soil are the source of all energy consumed by the populational groups of ecosystems;

- the Atmosphere and the Soil operate as transportation means for the $\mathrm{O}_{2}, \mathrm{CO}_{2}$, Water and Nutrients that the populational groups exchange between them;

- individuals of a populational group eating individuals of another populational group is also a means for the former group to receive energy from the latter one;

- the set of exchange processes operating in the ecosystem constitute a complex network;

- there are more than two types of objects being exchanged in the system.

Also, from the economical point of view, such system surpasses the conditions stipulated by the concepts introduced in the present paper, and an elementary economical analysis of ecosystems can only partially account for it. So, we restrict ourselves here to modeling just the following elementary economical exchanges present in Figure 6:

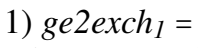

$\langle\text { Detrivores } /(\text { Water }+ \text { Nutrients }): \text { Soil }\rangle_{+} \overleftrightarrow{\rightleftarrows}^{+}\langle$Plants $/$Plants $\rangle$

where:

- $\langle$ Detrivores $/($ Water + Nutrients $):$ Soil $\rangle$ denotes that Detrivores deliver objects of types Water and Nutrients through the Soil to Plants;

- $\langle$ Plants/Plants $\rangle$ denotes that Plants deliver objects of type Plants directly to (be eaten by) Detrivores. 


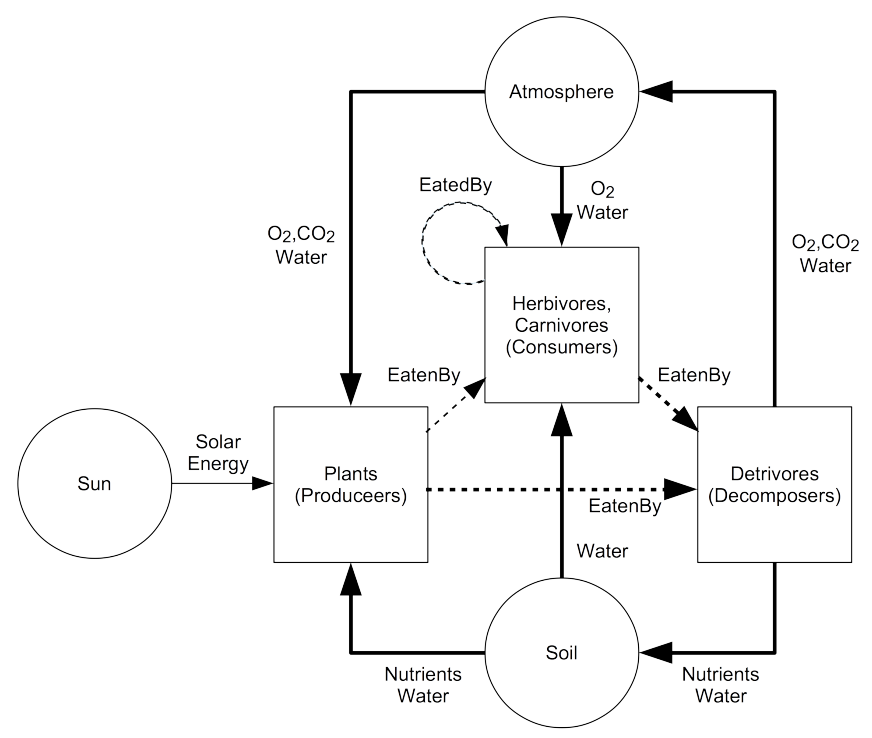

Figure 6. The general model of ecosystems, based on [7].

- Pop $^{t}=\left(\right.$ Plants $^{t}$, Herbivores $^{t}$, Carnivores $^{t}$, Detrivores $\left.^{t}\right)$

- a tuple of sub-populations;

- Org $^{t}=\left(\mathrm{O}_{2}^{t}, \mathrm{CO}_{2}^{t}\right.$, Water $^{t}$, Nutrients ${ }^{t}$, EatenBy $^{t}$, SolarEnergy $\left.^{t}\right)$

- a tuple of sets of exchange links, through which are exchanged the corresponding substances;

- MEnv ${ }^{t}=\left(\right.$ Atmosphere $^{t}$, Soil $^{t}$, Sun $\left.^{t}\right)$

- a tuple of material objects;

with:

- $O_{2}^{t}=\left\{\left(\right.\right.$ Detrivores $^{t}$, Atmosphere $\left.^{t}\right),\left(\right.$ Atmosphere $^{t}$, Plants $\left.^{t}\right)$,

$\left(\right.$ Atmosphere $^{t}$, Herbivores $\left.^{t}\right),\left(\right.$ Atmosphere $^{t}$, Carnivores $\left.\left.^{t}\right)\right\}$

- $\mathrm{CO}_{2}=\left\{\left(\right.\right.$ Detrivores $^{t}$, Atmosphere $\left.^{t}\right),\left(\right.$ Atmosphere $^{t}$, Plants $\left.\left.^{t}\right)\right\}$

- Water $^{t}=\left\{\left(\right.\right.$ Detrivores $^{t}$, Atmosphere $\left.^{t}\right),\left(\right.$ Atmosphere $^{t}$, Plants $\left.^{t}\right)$,

$\left(\right.$ Atmosphere $^{t}$, Herbivores $\left.^{t}\right),\left(\right.$ Atmosphere $^{t}$, Carnivores $\left.^{t}\right)$, $\left(\right.$ Detrivores $^{t}$, Soil $\left.^{t}\right),\left(\right.$ Soil $^{t}$, Plants $\left.^{t}\right)$,

$\left(\right.$ Soilt $^{t}$, Herbivores $\left.^{t}\right),\left(\right.$ Soil $^{t}$, Carnivores $\left.\left.^{t}\right)\right\}$

- Nutrients ${ }^{t}=\left\{\left(\right.\right.$ Detrivores $^{t}$, Soil $\left.^{t}\right),\left(\right.$ Soil $^{t}$, Plants $\left.\left.^{t}\right)\right\}$

- EatenBy ${ }^{t}=\left\{\left(\right.\right.$ Herbivores $^{t}$, Detrivores $\left.^{t}\right),\left(\right.$ Carnivores $^{t}$, Detrivores $\left.^{t}\right)$, $\left(\right.$ Plants $^{t}$, Detrivores $\left.^{t}\right),\left(\right.$ Plants $^{t}$, Herbivores $\left.^{t}\right)$,

$\left(\right.$ Plants $^{t}$, Carnivores $\left.^{t}\right),\left(\right.$ Carnivores $^{t}$, Carnivores $\left.\left.^{t}\right)\right\}$

- SolarEnergy ${ }^{t}=\left\{\left(\right.\right.$ Sun $^{t}$, Plant $\left.\left.^{t}\right)\right\}$

Figure 7. The detailment of the material agent society-based modeling of the ecosystem shown in Figure 6. 
2) ge $2 e x c h_{2}=$

$\langle\text { Detrivores/Water : Soil }\rangle_{+} \rightleftarrows^{+}$

$\langle($ Herbivores + Carnivores $) /($ Herbivores + Carnivores $)\rangle$

3) ge $2 e x c h_{3}=$

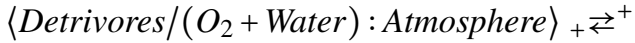

$\langle($ Herbivores + Carnivores $) /($ Herbivores + Carnivores $)\rangle$

4) $\mathrm{ge}^{2 \mathrm{exch}_{4}=}$

$\left\langle\text { Detrivores } /\left(\mathrm{O}_{2}+\mathrm{CO}_{2}+\text { Water }\right): \text { Atmosphere }\right\rangle_{+} \overleftrightarrow{\rightleftarrows}^{+}$

$\langle$ Plants/Plants $\rangle$

On the other hand, the sole elementary economic process present in the general model of ecosystems shown in Figure 6 is the one given by:

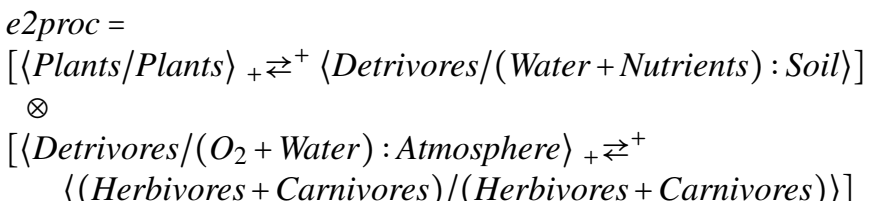

Thus, even with the limited modeling capability provided by the elementary concepts of economic systems introduced in this paper, we can cast at least a part of the general model of ecosystems given in Figure 6 in the form of an elementary economic system, as follows:

EES $_{\text {EcoSys }}^{t}=\left(\right.$ Group $^{t}$, Obj $^{t}, G E 2 B e h^{t}$, GE2Exch $^{t}$, GE2Proc $\left.^{t}\right)$

with:

- Group $^{t}=$ Pop $^{t}$

- because all of the populational sub-groups of the ecosystem participate, as elementary economical groups, in the elementary economic system;

- $\mathrm{Obj}^{t}=$

$\left\{\mathrm{O}_{2}, \mathrm{CO}_{2}\right.$, Water, Nutrients, Plants, Herbivores, Carnivores $\}$

- which are the objects exchanged by the elementary economical groups;

- GE2Beh ${ }^{t}=$ DeliverBehaviors $\cup$ ReceiveBehaviors

where:

DeliverBehaviors =

$\{$ deliver(Detrivores, Water, Carnivores), deliver(Detrivores, $\mathrm{O}_{2}$, Carnivores), deliver(Detrivores, $\mathrm{CO}_{2}$, Carnivores), deliver(Detrivores, Water, Herbivores), deliver(Detrivores, $\mathrm{O}_{2}$, Herbivores), deliver(Detrivores, $\mathrm{CO}_{2}$, Herbivores), deliver(Carnivores, Carnivores, Detrivores), deliver(Herbivores, Herbivores, Detrivores), deliver(Detrivores, Nutrients, Plants), deliver(Detrivores, Water, Plants), deliver(Detrivores, Water, Plants), deliver(Detrivores, $\mathrm{O}_{2}$, Plants), deliver(Detrivores, $\mathrm{CO}_{2}$, Plants), deliver(Plants, Plants, Detrivores) $\}$ and ReceiveBehaviors are the corresponding reception behaviors;

- which are the group elementary economic behaviors;

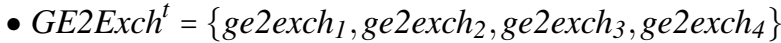

- which are the group elementary economic exchanges;

- $G E 2$ Proc $^{t}=\left\{e 2\right.$ proc $\left.^{t}\right\}$

- which is the only group elementary economic process.

Given the above elementary economic model $\left(E E S_{E c o S y s}^{t}\right)$, it should be possible to determine, for any given ecosystem (EcoSys) that complies with the general model of ecosystems shown in Figure 6, if it is, at any given time, in material or in the operational equilibrium, whenever the required values of temporal rates of behaviors and material outcomes of exchanges are provided.

Notice that, in $E E S_{E c o S y s}^{t}$, we have determined all reinforcement signals to be positive for the sake of the example. In any concrete analysis, the correct signals should be appropriately determined.

\section{Conclusion}

The concepts introduced in the present paper seem to be the most elementary economical concepts that can fit the basic features of energy systems of material agent societies, as they were defined in [1].

The definition of full-fledged economic systems for material agent societies is reserved for future work. It will require the lifting of many of the constraints that are intrinsic to the elementary systems. For instance:

- allowing for more than two types of objects in economic exchanges;

- accounting for indirect operant conditionings, through chains of indirect partners;

- removing the impediment of cycles in economic processes, leading to complex networks of arbitrarily interlinked economic processes and allowing for behaviors capable of indirect self-reinforcements.

We remark that we have no knowledge of other reports dealing with the concepts introduced here, analogously to what happened in [1].

\section{Acknowledgements}

The author thanks the anonymous referees for their very useful remarks.

\section{References}

[1] COSTA, A. C. R. Energy systems in material agent societies. RITA - Revista de Informática Teórica e Aplicada, SBC, Porto Alegre, v. 24, n. 2, p. 130-144, 2017.

[2] ARENDT, H. Human Condition. Chicago: University of Chicago Press, 1958. 
[3] BRAUDEL, F. Civilisation Matérielle, Économie et Capitalisme, XVe-XVIIIe siècle. 1-Les Structures du Quotidien. Paris: Armand Colin, 1986.

[4] HOMANS, G. Social Behavior - Its Elementary Forms. New York: Harcourt, Brace \& World, 1961.

[5] SKINNER, B. F. The Behavior of Organisms: an experimental analysis. Acton: Copley Publishing Group, 1991.

[6] COSTA, A. C. R. Ecosystems as agent societies, landscapes as multi-societal agent systems. In: ADAMATTI, D. F. (Ed.). Multiagent Based Simulations Applied to Biological and Environmental Systems. Hershey: IGI Global, 2017. p. 25-43.

[7] PIDWIRNY, M. Fundamentals of Physical Geography (2nd Ed.). [S.1.]: PhysicalGeography.net, 2009. Available online at http://www.physicalgeography.net.. Acesso em: 09/09/2018. 